\title{
VIOLÊNCIA E SEGURANÇA CIDADÃ ${ }^{1}$
}

\author{
Maria Tereza Sadek \\ Pesquisadora do IDESP e professora da USP \\ Email: tesadek@usp.br
}

\section{Resumo}

A crise da Segurança Pública no Brasil é algo que afeta os fundamentos do Estado Moderno, constituindo-se na mais séria ameaça à ordem constituída. E quais seriam as causas desse problema? De um lado, analistas defendem que as causas são eminentemente estruturais, de natureza econômica. De outro, há os que defendem a falta de coesão social, as dificuldades decorrentes dos padrões brasileiros de sociabilidade. Embora as duas teorias apresentem aspectos importantes da questão, elas não são suficientes para explicar o grau de crescimento da violência no Brasil nos anos recentes. Em face dessa dificuldade é necessário repensar a própria formulação do problema, observando-se o chamado "crime organizado" de uma nova ótica, que leve em conta a natureza do delito e os possíveis ganhos para quem os pratica.

Palavras-chave: violência no Brasil, segurança pública, cidadania e justiça

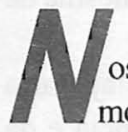

os últimos tempos, nenhum tema tem chamado tanta atenção e mobilizado tantos debates quanto a violência e a segurança cidadã. Diariamente, noticiários abrem espaços para cenas de violência, descrevendo atos que atentam contra a segurança e uma vida minimamente civilizada. Compõem o outro lado deste quadro as deficiências do Estado

\footnotetext{
' Palestra apresentada no Simpósio sobre Violência e Causas da Criminalidade, realizado pelo Movimento do Ministério Público Democrático em conjunto com o Núcleo de Estudos da Violência da USP e o Instituto São Paulo contra a Violência, em 29 de novembro de 2002.
} 
e o crescimento de aparatos policiais privados. Entretanto, o fácil consenso quanto ao repúdio, ao temor e à censura à violência, rapidamente se desfaz quando se trata de procurar suas causas e possíveis soluções.

De problema circunscrito à área policial, a violência tem cada vez mais se transformado em uma questão que consta de agendas políticas e econômicas. Governantes, postulantes a postos públicos são instigados a discorrer sobre o tema. Programas de investimento econômico passaram a ter a violência entre seus itens de cálculos de risco. Deste ponto de vista pode-se dizer que o tema adquiriu nos últimos tempos, um perfil distinto daquele que possuía em um passado não muito distante.

Apesar das singularidades do presente, a ausência de segurança remete-nos aos próprios fundamentos do Estado Moderno. Hobbes $(1974)^{2}$ afirmava que os homens aceitam abondar o estado de natureza e constituir uma sociedade movidos pela razão e pelo medo. A insegurança é a característica central do estado de natureza, traduzindose no medo da morte ou na constante ameaça de morte, de destruição e toda sorte de incertezas. A razão aponta os meios adequados para superar esta situação: a transferência de poder para um homem ou uma assembléia de homens - ou seja, o Estado - cuja função primordial é a segurança dos cidadãos. A segurança é a finalidade do Estado. Em nome deste objetivo os homens obedecem e sujeitam-se à soberania. $\mathrm{O}$ único motivo legítimo que justificaria a desobediência é a incapacidade do Estado de realizar sua finalidade. A rigor, pode-se afirmar que se trata de uma definição mínima de Estado: a ausência de segurança significa ausência de Estado. Esta concepção hobbesiana não diz respeito ao regime - se democrático ou não - mas à condição mesma de existência do poder público.

Retomar a visão hobbesiana sobre o estado pode nos ajudar a elaborar uma primeira aproximação aos problemas da violência e da segurança pública. Ou seja, entender a violência como o reverso do Estado, como a mais séria ameaça à ordem constituída.

A possível validade desta aproximação não é, entretanto, suficiente para a apreensão completa do problema. É necessário dar um segundo passo, capaz de indagar sobre as "causas" da violência. É

${ }^{2}$ Ver especialmente Leviatã, livros I e II. 
sabido que para Hobbes a violência tem origem fundamentalmente em atributos naturais do homem, mesmo porque a vida em sociedade só é possível após a existência do Estado. Quais as origens sociais da violência? Ou seja, é possível encontrar explicações que tenham origem no homem social, que enquadrem as características psicológicas do homem natural na vida histórica e social? $\mathrm{Ou}$, em outras palavras, como explicar a violência dos pontos de vista sociológico e histórico?

Tradicionalmente, duas correntes interpretativas têm proposto respostas para as possíveis origens da violência. Há, de um lado, aquelas que sustentam que a criminalidade e a violência são fenômenos que têm origem essencialmente em fatores de natureza estrutural, mais especificamente, em variáveis econômicas. Desta forma, a pobreza, o desemprego, a desigualdade socioeconômica, a marginalização são variáveis decisivas para explicar diferenciações nos índices de violência. Por outro lado, tem-se um conjunto de teorias que buscam as causas da violência em variáveis de ordem social, mais propriamente em fatores relacionados ao grau de coesão social.

A adesão a uma ou outra dessas correntes implica diferentes prioridades no que se refere a possíveis intervenções do poder público e/ou da sociedade civil para enfrentar o problema.

Grosso modo, pode-se dizer que o primeiro tipo de explicação a centrada em variáveis econômicas - recebeu durante um longo período um grande apoio no meio acadêmico e político. De fato, de um ponto de vista macro é relativamente fácil encontrar correlações entre variáveis econômicas e violência. No Brasil, contudo, importantes estudos recentes $(B E A T O, 1998)^{3}$ chegam à conclusão de que as evidências empíricas disponíveis não permitem sustentar a hipótese segundo a qual o desemprego, a pobreza e a crise econômica estejam relacionados casualmente com taxas de criminalidade.

Dados empíricos revelam, entretanto, que os índices de violência têm crescido exponencialmente, colocando em risco a convivência social. Em 20 anos, o número de homicídios no país aumentou $273 \%$ sete vezes mais do que o percentual de crescimento da população, que foi de $37 \%$, entre 1979 e 1988 .

\footnotetext{
${ }^{3}$ Um dos mais significativos estudos sobre a criminalidade foi desenvolvido .
} 
Apesar da correlação entre variáveis econômicas e violência não ser a mais significativa, não haveria como ignorar que a iníqua distribuição de renda que tem marcado a sociedade brasileira possui efeitos nos índices de criminalidade. É indiscutivelmente por demais alto, entre nós, o grau de desigualdade social. E mais ainda: ao longo dos últimos 20 anos não se verificou melhoras significativas na distribuição da riqueza, tendo permanecido imensa a distancia que separa um pequeno grupo de pessoas excessivamente ricas de um muito grande contingente de pobres.

Esta situação certamente produz consequiências, ainda que não determinantes, sobre o tipo de convivência social. Dificilmente, uma sociedade que ostenta tamanha desigualdade nos níveis de distribuição de riqueza poderia patrocinar padrões minimamente civilizados de relações sociais.

Uma vez descartada, ou pelo menos minimizada a causalidade de origem econômica, caberia examinar a influência de outros fatores. Evocando os fundamentos da corrente sociológica que se apóia em fatores de ordem social, ou, mais precisamente, no significado da coesão social, nota-se, uma vez mais, que as condições brasileiras são bastante desfavoráveis. $\mathrm{O}$ processo de urbanização deu-se numa velocidade extremamente rápida, provocando, num intervalo de apenas 40 anos (de 1940 a 1980), uma completa inversão na distribuição da população economicamente ativa dedicada ao setor primário e aos demais setores, bem como ocorreu um enorme predomínio de concentrações urbanas sobre a população rural. As consequiências desses processos não poderiam deixar de ser perversas no padrão de sociabilidade, implicando desenraizamento, quebra de laços primários e toda sorte de fenômenos relacionados a um tipo de urbanização que não foi acompanhada pela implantação de serviços públicos básicos.

Evidências empíricas internacionais mostram que centros urbanos inchados, deterioração de vínculos proporcionados por laços primários, desorganização familiar, ausência de consenso moral e normativo, são fatores que estimulam a violência. Acrescentando-se a estes fatores, a pobreza, as precárias condições de vida, a marginalização, intensos movimentos migratórios e, sobretudo, a extrema desigualdade social, tem-se um quadro bastante propício a um estilo de vida com baixos padrões de civilidade. 
Se os quadros apresentados acima permitem supor a existência de um cenário favorável à violência, eles não são suficientes para fundamentar o grau de violência a que se tem assistido nos últimos anos. Dizendo-o de outra forma: o "desafio" explicativo está no fato de que o aumento nos níveis de criminalidade tem-se dado de forma muito mais do que proporcional muito mais do que os índices de desigualdade ou de desenraizamento social fariam supor.

Em face a dessas deficiências, estudos recentes buscam listar outras variáveis relacionadas à criminalidade. Segundo muitos analistas, outros fatores devem ser igualmente apreciados e, talvez, tenham um impacto ainda mais determinante sobre a criminalidade que as variáveis econômicas e sociais. Entre eles, os mais importantes são: a impunidade; a descrença nas instituições do sistema de justiça; a fragilidade do sistema de justiça criminal; a corrupção; o comportamento das forças policiais; a existência de cidadãos armados; grupos de extermínio; chacinas e linchamentos; o papel da mídia.

Examinando-se esses achados, podem-se levantar duas hipóteses: uma que contemple um número maior de variáveis, dando peso a cada uma delas; outra, que busque qualificar a própria violência. No primeiro caso, corremos o risco de, no limite, não termos explicação alguma, a medida que ao adicionarmos um número sempre maior de fatores chegamos a um modelo estatístico que pode significar "tudo explica tudo", que é o mesmo que "nada está sendo explicado". Contudo, talvez, este seja um passo indispensável para repensar a própria formulação do problema. Pois, de alguma forma, as teorias tradicionais - apesar de suas diferenças - partem de um suposto semelhante: a carência e/ou a privação impulsionam a violência.

Diante das referidas deficiências explicativas caberia indagar se não se trata de qualificar a violência, distinguindo no interior do fenômeno geral "violência" tipos distintos de delitos. Ou seja, caberia perguntar: Estamos, no presente, referindo-nos a um mesmo tipo de violência ou de crime que marcou o passado? Ou, ao contrário, temos convivido nos últimos anos com um tipo de crime, com um tipo de violência que pouco tem a ver com carências e privações, mas com uma nova forma de organização, com uma nova forma de riqueza, como se tem caracterizado o chamado "crime organizado"? Caso esta hipótese seja plausível, ela 
tem implicações. E a primeira delas seria, inclusive, inverter o raciocínio tradicional, ou seja, buscar associações não mais entre criminalidade e pobreza, mas entre criminalidade e riqueza. $\mathrm{O}$ suposto aqui é que centros mais prósperos criam oportunidades para delitos, não apenas devido ao aumento nas oportunidades de praticá-los, à ausência de controles sociais, mas, sobretudo, devido à criação de ambientes propícios a um novo tipo de criminalidade. Trata-se, pois, de examinar a natureza dos delitos, quem os pratica, contra quem, com que tipo de ameaça, com que tipo de ganho, com qual tipo de conexão e organização.

\section{Impunidade}

Ainda que se questione a validade de se levar em consideração uma única variável para explicar a criminalidade, não se pode minimizar a importância da avaliação pública sobre o fenômeno. Inúmeras pesquisas de opinião têm demonstrado a existência de dois traços complementares. De um lado, a percepção do crescimento da violência e da ausência de políticas públicas capazes de enfrentar com sucesso o problema. De outro, o que poderia ser identificado como a "banalização" da violência. Neste caso, o convívio com a violência tem implicado a "naturalização" do crime e a displicência na busca de canais estatais para a sua solução. Ou seja, é como se houvesse crescido a tolerância com certos tipos de violência e o reconhecimento de que se trata de um problema sem solução. Assim, elabora-se uma explicação que justifica tanto um fechar de olhos para a violência que acomete o vizinho, quanto a busca de soluções privadas, ainda que inteiramente contra a lei. Crescem, desta forma, os aparatos de vigilância privada, os grupos de extermínio, os "justiceiros", o número de cidadãos armados, enquanto decrescem substantivamente o número de indivíduos que se dispõem a registrar a ocorrência de um delito e de cidadãos que manifestem algum tipo de solidariedade à vitima da violência.

Este quadro é impulsionado pela impunidade. A ausência de correspondência entre o expressivo número de crimes e de penalidades é apontada como o principal indicador empírico de impunidade no país. A desproporção é válida tanto para delitos de homicídio como para os chamados crimes de colarinho branco. Esta desproporção, entretanto, 
não se distribui de forma igual nem quando se considera o tipo de crime - contra a vida ou contra o patrimônio -, nem quando se leva em conta a distribuição espacial - áreas urbanas ou rurais- e menos ainda quando se compara o agente - qualificações socioeconômicas (rico e pobre; grau de escolaridade; cor, profissão, etc.).

Não é necessário nos alongarmos neste tema. Expressões populares sintetizam com clareza os limites na aplicação da lei, a descrença no sistema judicial, a desigualdade real quando contrastada com a igualdade apregoada nas leis: "rico não vai para a cadeia"; "na cadeia só se encontra preto, pobre e prostituta"; "é mais fácil encontrar na cadeia um ladrão de galinha do que um ladrão de milhão"; "o crime compensa"; "doutor não vai preso".

\section{Razões para a Impunidade}

Embora muitas vezes seja difícil esclarecer ou responsabilizar alguém por um delito, a defasagem entre o número de crimes cometidos e os que chegam a ser julgados não deixa dúvidas que há um buraco negro proposital. Neste buraco, o envolvimento de policiais em delitos ocupa um espaço importante.

Costuma-se dizer que no Brasil prende-se muito e processa-se pouco. O anedotário popular consagrou a expressão: "A polícia prende e a justiça solta". Esta é uma das faces do problema. A outra, mais importante ainda, é que está nas mãos da polícia a investigação e, conseqüentemente, o destino do detido. Aqui, a corrupção tem um papel fundamental. Ou seja, há meios de invalidar provas, de engavetar processos, de forjar testemunhas.

Responsabiliza-se o anacronismo do Código do Processo Penal por parte da impunidade, uma vez que nele deixam de estar devidamente contempladas as mudanças por que passou a sociedade brasileira nos últimos anos. Sublinha-se que são penalizados delitos menores enquanto os mais importantes têm sua capacidade de ofensa social minimizada. A possível verdade deste fato não diminui a influência de outros fatores: morosidade da justiça; extrema desigualdade nas possibilidades de defesa de direitos individuais, quando se consideram os assistidos por advogados pagos e aqueles 
que se utilizam de defensores públicos; excessivo formalismo nos procedimentos judiciais; o sistema recursal.

\section{Controle da Violência Policial}

Embora caiba às forças policiais um importante papel no controle da violência, assiste-se, com frequiência, além do envolvimento destes agentes em crimes, à perpetração de atos de absoluto desrespeito aos mais elementares direitos da cidadania. A cultura da violência certamente estimulada durante o período autoritário - expressa-se desde a forma de abordar o suposto criminoso até a forma de obtenção de provas, com interrogatórios fundados em tortura física e psicológica. Deste ponto de vista, a imagem dos policiais longe de ser identificada com a dos agentes da ordem, como dispõem os textos legais, tem sido muito mais associada com a violência sem limites, com o arbítrio.

Legalmente, algumas iniciativas têm se destacado no exercício do controle da violência, de abusos de poder e de corrupção praticados por policiais. Entre elas, chamaríamos a atenção para: Corregedoria das Polícias civil e militar, Ouvidoria de Polícia e Ministério Público.

A Corregedoria sempre teve a incumbência de punir policias que cometam abusos no exercício da função. Esta atribuição, entretanto, nunca foi muito efetiva. Sempre se considerou que o "espírito de corpo" seria mais forte do que um julgamento imparcial. Contudo, pressões por parte da sociedade civil, particularmente de grupos vinculados aos direitos humanos, têm provocado mudanças.

As Ouvidorias da Polícia são relativamente recentes no país. A primeira a ser instalada foi a de São Paulo, criada por decreto em 1995. Apesar do baixo número de punições, é inegável que o trabalho da Ouvidoria, sobretudo em estados em que a instituição já adquiriu legitimidade popular, vem provocando efeitos tanto no desempenho das polícias, como no sentimento geral a respeito da impunidade.

A Constituição de 1988 conferiu ao Ministério Público, entre outras atribuições, o controle externo da atividade policial. Promotores e procuradores, manifestam contudo, um relativo consenso de que esta função está longe de ter um desempenho satisfatório. Em muitos estados, a instituição pouco tem atuado neste sentido, e naqueles em que alguma 
coisa tem sido feita, trata-se muito mais do resultado de uma atuação individual do que de uma política institucional. Muitos motivos poderiam ser arrolados para explicar esta deficiência: resistência de delegados de polícia; ausência de quadros na instituição para o exercício desta atividade; falta de vontade política; debilidade dos mecanismos de controle e fiscalização nas mãos dos integrantes do Ministério Público, tornando muito altos os custos do exercício desta função.

\section{Mentalidade}

Durante o início do período republicano, dizia-se que o problema social era um problema de polícia. À polícia cabia a solução de conflitos. Ou seja, podia-se, traduzir solução por destruição, extirpação. Embora já não seja dominante, está ideologia ainda encontra defensores. Basta lembrar os esquadrões da morte, apoios velados a soluções próximas da barbárie e mesmo o número expressivo de adeptos da pena de morte.

Embora seja inquestionável que a criminalidade se beneficie da ausência do poder público, seu significado não se esgota na repressão policial. A tradição jurídica "conservadora" tem na repressão sua mola mestra. Nesta linha podem ser enquadrados muitos juristas que vêem no aumento ou na severidade das penas a solução para a criminalidade. Esta concepção tem sua versão mais contemporânea na conhecida "tolerância zero", ou seja, penalizar fortemente mesmo pequenos delitos.

Apesar do apoio popular a estes argumentos, não se pode dizer que não tenham ocorrido mudanças de mentalidade, influenciadas, sobretudo, pela força dos ideários dos "direitos humanos".

Ao lado de afirmações que desqualificam os direitos humanos, tentando convencer a população de que se trata de um discurso para proteger bandidos, há uma nova consciência.

\section{Propostas}

Um dos principais problemas quando se buscam soluções para a violência, refere-se ao fato de que há apreciáveis dificuldades de produzir informações sobre a criminalidade e de lidar com elas. Além de dados não inteiramente confiáveis, qualquer solução fere interesses e, 
conseqüentemente, provoca resistências capazes de anular possíveis efeitos de medidas inovadoras. Por outro lado, parece cada vez mais claro que não há soluções milagrosas, nem capazes de produzir resultados no curtíssimo prazo. Isto, sem dúvida, é um fator complicador, porque governantes, atentos aos índices de popularidade, preferem alocar recursos em áreas de maior visibilidade. Qualquer possibilidade de enfrentar questões estruturais, que se manifestam em uma herança de injustiça social - que exclui parte significativa da população do acesso a condições mínimas de dignidade e cidadania - torna centrais as políticas públicas redistributivas ${ }^{4}$, as garantias legais e sua efetividade.

Considerem-se, ainda, especificidades nos âmbitos de atuação dos governos federal, estadual e municipal.

Cabe ao governo federal, por exemplo, coibir o contrabando de armas, reprimir o tráfico de drogas, debelar quadrilhas interestaduais que atuam de forma organizada. Dado o significado e a proporção do crime organizado em face dos delitos de natureza tradicional, é extremamente relevante o papel da União. A tarefa mais importante dos governos estaduais refere-se ao comando da polícia.

Uma das propostas sempre ventilada é a utilização do exército como força policial para o combate da violência urbana. Isto implicaria, obrigatoriamente, mudança constitucional. Durante o período militar, a Constituição de 1967 dava amplas competências às forças armadas, inclusive para controlar e supervisionar a maior parte das atividades das Polícias Militares. Cabia ao Ministério do Exército controlar os efetivos, a organização, o armamento, a instrução, por meio da Inspetoria Geral das Polícias Militares. A Constituição democrática de 1988 retirou essas competências do exército. Além disso, deve ser dito que falta ao exército, treinado para situações de guerra, quadros com preparo para enfrentar os chamados delitos do cotidiano: roubos, furtos, tráfico de drogas, assassinatos, seqüestro.

Outra proposta refere-se a mudanças legislativas. Julga-se que com leis mais severas haveria uma diminuição no número de delitos.

\footnotetext{
${ }^{4}$ Relatório do Programa das Nações Unidas para o Desenvolvimento (1999) mostra que o gasto social do Estado não tem chegado aos mais pobres. Do total de gasto público com pensões, por exemplo, mais de $80 \%$ são absorvidos pelos $40 \%$ com renda mais alta. Os dois quintos mais pobres não chegam a receber $9 \%$.
} 
Toma-se como exemplo positivo os Estados Unidos. Naquele país temse uma legislação extremamente punitiva e conservadora. A população carcerária chega hoje à casa dos dois milhões, a maior do mundo tanto em termos absolutos como relativos - há 731 presos para cada 100 mil habitantes. No Brasil, segundo relatório do Ministério da Justiça, a população carcerária aumentou $30,5 \%$ nos últimos cinco anos, atingindo 193 mil presos. Deste total, 58 mil permanecem detidos em distritos policias - portanto, em situação extremamente precária. $O$ índice é de 124,8 presos para cada 100 mil habitantes. ${ }^{5}$

Ainda na esfera legislativa, mas com uma perspectiva oposta à conservadora, defende-se uma maior utilização de penas alternativas. O exministro da Justiça, José Carlos Dias, elaborou um projeto de reforma do Código Penal e da Lei de Execuções Penais baseando-se no suposto de que o regime fechado para o cumprimento de pena só deve ser utilizado para criminosos que ofereçam perigo à sociedade. "Dizer que a prisão reeduca alguém é balela; cadeia é um instrumento de contenção social", afirma. ${ }^{6}$

A proposta mais discutida refere-se à união das duas forças policiais: a Polícia Civil e a Polícia Militar. Esta modificação tem a oposição dos integrantes das duas polícias que chegaram apontar na iniciativa, suposta inconstitucionalidade.

O governo federal, durante os mandatos de FHC, lançou seguidos planos para a área da segurança pública, salientando a importância do treinamento de policiais, da construção de novos presídios, da ampliação do efetivo da Polícia Federal, da alteração de pontos do Código Penal. O último plano foi levado ao conhecimento do público em 19 de junho de 2000 e recebeu acirradas críticas de estudiosos do tema. Julga-se que se trata de "uma colcha de retalhos", com 124 medidas, incapazes de enfrentar o problema. Além disso, o referido projeto não estabelecia prioridades.

${ }^{5}$ A despeito da relevância da discussão sobre o Código Penal, é necessário que se leve em conta que o aumento da população carcerária não correspondeu no Brasil a uma redução significativa nos índices de criminalidade.

${ }^{6}$ No Brasil, apenas $6 \%$ dos presos cumprem pena em regime aberto, número considerado baixo por especialistas. Sobram vagas para as penas alternativas. Por exemplo, apesar do governo paulista reservar aos condenados 1.942 postos de trabalho em serviços à comunidade, só 327 deles foram preenchidos pela Justiça, responsável pela aplicação da medida. 
Ainda que seja difícil chegar a soluções consensuais, é cada vez mais claro que a violência tornou-se um dos problemas mais relevantes para o cidadão. Seu impacto sobre o cotidiano, sobre a vida social tem mostrado seu extraordinário poder de deterioração das instituições e da convivência democrática e civilizada. A tentação de adotar soluções mágicas e imediatas pode colocar em risco a legalidade democrática. A obrigação do poder público de responder às demandas sociais, agindo com firmeza, não significa que se devam abandonar as normas legais; que as forças policiais se igualem aos criminosos. A urgência na elaboração de políticas publicas que combatam a violência não pode fazer com que a "guerra de todos contra todos" destrua o Leviatã.

\section{Referências}

BEATO, Cláudio. Determinantes da criminalidade em Minas Gerais. Revista Brasileira de Ciências Sociais, São Paulo, v.13, n.37, p.74-89, 1998.

HOBBES, Thomas. Leviatã ou matéria: forma e poder de um Estado eclético e civil. São Paulo: Abril, 1974.

RELATÓRIO do Programa das Nações Unidas para o Desenvolvimento (PNUD). Lisboa: Trinova, 1999. 